\title{
CORRECTION
}

\section{OCCURRENCE OF LEUKAEMIA FOLLOWING GENE THERAPY OF X-LINKED SCID}

Donald B. Kohn, Michel Sadelain and Joseph C. Glorioso

Nature Rev. Cancer 3, 477-488 (2003)

On page 482 of this article, a recent report by S. Hacein-Bey-Abina et al. was inadvertently omitted from the list of citations in the legend of Figure 2a. The text and reference should have been:

See also REFS 14,18 and 99 .

99. Hacein-Bey-Abina, S. et al. A serious adverse event after successful gene therapy for X-linked severe combined immunodeficiency. N. Engl. J. Med. 348, 255-256 (2003).

The first report of a monoclonal T cell lymphoproliferative syndrome, detected 30 months after gene therapy. Within four months, the patient developed a major hyperlymphocytosis and hepatosplenomegaly. A single vector integration was found within the LMO2 locus, associated with aberrant LMO2 expression.

The authors also want to point out that Dr Fischer and his colleagues describe the clonal expansions that were observed in their two patients as 'leukaemia-like lymphoproliferative disease'. The general term of 'leukaemia', without further qualification, was used in this review. 